\title{
Arquivo - máquina de (des)montar
}

\section{Archive - machine of (dis)assemble}

\section{João Nilson Alencar* \\ UEM}

Resumo: Este texto discute o papel do arquivo na contemporaneidade, reabrindo o debate sobre as visões e abordagens do mesmo. Por um lado, reivindica a ideia de espaço neutro, esvaziado, em direção a um conceito de devir, de ur-história, e menos como lugar físico, fechado, acabado, portador de um sentido a priori. O arquivo se propõe, assim, como aventura, descaminho, roteiro. Ao mesmo tempo, aborda material inédito do arquivo de Murilo Rubião, reorganizando a leitura da própria produção canônica do escritor mineiro, realizando a operação denominada por Walter Benjamin como desempacotando a biblioteca da literatura brasileira como um todo. O estudo debruça-se sobre a pasta do arquivo denominado Anotações antigas para contos improváveis, encontrado no Arquivo dos Escritores Mineiros da Universidade Federal de Minas Gerais.

Palavras-chave : Arquivo. Literatura Brasileira. Murilo Rubião.

Abstract: This text discusses the role of the contemporary archive , reopening the debate on the views and approaches of it. On the one hand, claims the idea of neutral space , emptied, toward a concept of becoming, the ur- history and less as a physical place, closed, finished , carrying a sense a priori. The archive is proposed, as well as adventure, embezzlement, script . At the same time, it deals with new material from Murilo Rubião file, rearranging a reading of the canonical production of mineiro writer, performing the operation called by Walter Benjamin as unpacking the library of Brazilian literature as a whole. The study focuses on the folder the file named Old Notes for unlikely tales, wich is found in Arquivo dos Escritores Mineiros of Universidade Federal de Minas Gerais.

Keywords: Archive. Brasilian Literature. Murilo Rubião.

\section{Des-arquivar 0 arquivo}

O século XIX é o sonho do qual se deve despertar: um pesadelo que pesará sobre o presente enquanto permanecer intacto seu fascínio. As imagens do sonho e o despertar desse sonho comportam-se, segundo Benjamin, como a expressão e a interpretação; para ele, somente a interpretação das imagens devolveria o fascínio.

Walter Benjamin sobre Rolf Tiedemann

Há muitas formas de começar este ensaio. Assim com Clarice, em A hora da estrela, uma sucessão de nomes aparece. Esta sucessão, revelada no

\author{
* Professor na \\ Universidade Federal \\ de Santa Catarina \\ (UFSC) / alencarjn@ \\ hotmail.com \\ Estudou Letras \\ Português-Inglês \\ Mestrado em \\ Literatura \\ Brasileira(UFSC) \\ Doutorado em Teoria \\ Literária(UFSC-UBA) \\ Pós-Doutorado em \\ Estudos Literários \\ (UFMG)
}


início do texto, põe, de imediato, a questão do jogo autoral (na verdade, um narrador, Rodrigo, assume essa voz), bem como simula uma confissão, num jogo dúbio em que o leitor é convidado a transitar entre uma enunciação: da escritora/do narrador. Essa oscilação marca uma ideia de modernidade que também vigorou para os primeiros teóricos que pensavam igualmente uma literatura chamada de fantástica. Vide Tzetan Todorov, Louis Hay e tantos outros. Voltemos à oscilação. Vamos ao arquivo. Miremos Murilo, o Rubião.

$\mathrm{O}$ arquivo, assim como $\mathbf{O}$ neutro de Roland Barthes (BARTHES, 2003), parece estar contaminado daquilo que o escritor francês chamou, retomando Bacon, a propósito das manias de Fantasmas da caverna ${ }^{1}$. Estamos diante da questão fantasmática, o que implicaria, via de regra, pensar a questão da origem. No livro introdutório aos Retratos em Clarice Lispector, deparamo-nos com alguns quadros pintados pela escritora. São quadros instigantes, porque, longe de todo o realismo, próprio dela, o tema da origem está presente. Chamam a atenção os quadros Interior da gruta (1960) e outro, Gruta, já de 1975, com que, relacionando com o pré-título de A hora da estrela, os quadros, antecipando a narrativa de Ricardo Iannace (IANNACE, 2009), tematizam essa questão. Comenta Ricardo:

Data de 1964 a edição de A legião estrangeira. Nessa tiragem a obra se apresenta dividida em duas seções: na primeira figuram os contos; na segunda, as crônicas: "Esta segunda parte se chamará, como uma vez me sugeriu o nunca assaz citado Otto Lara Resende, de 'Fundo de gaveta'”. Aproveita Clarice Lispector, na sumária explicação, para mencionar Manuel Bandeira, remetendo o leitor à Consoada: “a casa limpa, a mesa posta, com cada coisa em seu lugar.” Mas reconhece que nos fundos das gavetas se preservam, independentemente de os recantos de uma casa estarem adulterados pela arrumação, souvenirs preciosos. E pergunta o que fazer com aqueles escritos suspeitos à publicação: "Por que publicar o que não presta?” Ao que responde: "gosto de um modo carinhoso do inacabado, do malfeito, daquilo que desajeitadamente tenta um pequeno voo e cai sem graça no chão.”2

Há que se ver aqui igualmente o tema do inacabado, do imperfeito..., com que o tema do arquivo está plenamente contemplado. O arquivo é origem. Espólio conservado durante anos, na dupla função de guardar, preservar, ou, em última estância, de não esquecer. A origem, no sentido pleiteado por este ensaio, nada tem a ver com a leitura literal que o termo é empregado pela tradição crítica. Não se trata de um ponto inicial, visto como o princípio de todas as coisas. Por outro, trata-se de um ponto de partida, uma Ur-história, ou ainda, com Deleuze, um dispositivo. Susan Buck-Morss, em Dialética do olhar (BUCK-MORSS, 2002, p.94), retomando Benjamin, afirma que a "ur-história "trata as origens históricas do presente: a história natural se torna ur-história. Seu alvo não é só polemizar contra o nível ainda bárbaro da idade moderna, mas elevando a polêmica à teoria histórico-filosófica,
${ }^{1}$ BARTHES, Roland. O neutro. Trad. Ivone Castilho Benedetti. São Paulo : Martins Fontes, 2003, p.183.
${ }^{2}$ IANNACE, Ricardo. Retratos em Clarice Lispector - Literatura, pintura e fotografia. Belo Horizonte : UFMG, 2009, p.41, grifos meus. 
desvelar a essência da nova natureza como algo ainda mais efêmero, mais fugaz que a idade antiga. A história natural como ur-história significa sublinhar o caráter pré-histórico da pré-história burguesa.” Em outro texto, A tela do cinema como prótese de percepção ${ }^{3}$ (BUCK-MORSS, 2009), a escritora discorre sobre a necessidade que o cinema tem de ficcionalizar os fatos (a guerra, por exemplo), pleiteando a tela como prótese, com o que poderíamos estender esse sentido para o arquivo, na medida em que não é o material em si, bruto, armazenado, que constitui sua riqueza. Esta é fruto de uma trama, de uma ficcionalização, o que não evitaria uma espécie de 'violência':

Na tela, as imagens moventes têm um significado presente, a despeito da ausência de corpos de carne e osso, que, por isso, se tornam uma questão indiferente. O que conta é o simulacro, não o objeto corpóreo por detrás dele. (...)Nos termos de Baudrillard, o código sobrepõe-se e domina o significado (...) Uma vez que esta redução [a própria lógica do código] tenha lugar, uma vez que a iminência simulada do objeto reduzido do cinema seja a fonte do significado, então uma espécie de violência se torna possível. Não falo só da violência de emoldurar e montar que corta a realidade, desmembra o corpo e esquarteja cada aspecto do continuum da realidade no processo de construir a imagem. Estou falando da violência da própria percepção protética.(BUCK-MORSS, 2009, pp. 16-17-18, grifo meu.)

Para Gilles Deleuze, é preciso pegar as coisas para extrair delas as visibilidades, feitas de regime de luz, cintilações, reflexos, clarões : “É como se o arquivo fosse atravessado por uma grande falha, que põe, de um lado, a forma do visível, de outro, a forma do enunciável, ambas irredutíveis. E é fora das formas, numa outra dimensão, que passa o fio que as costura uma à outra e ocupa o entre-dois.”. Com Didi-Huberman, esta questão está formulada através da necessidade de invenção de uma imagem (a propósito da Caixa negra de Tony Smith), transformada em verdadeiros blocos de latência:

Como se a invenção de uma imagem, por mais simples que seja, correspondesse primeiro ao ato de construir, de fixar mentalmente um objeto-questão, se posso dizer. Algo como aqueles cofrezinhos de chumbo, de ouro ou de prata que, nas fábulas de nossa infância ou de nossa literatura, encerram os destinos ou os desejos inconscientes de seus heróis. (DELEUZE, 2004, p.121).

Este outro lugar, fora das formas, e esta invenção da imagem de que falam Deleuze e Didi-Huberman, necessários para a costura entre o visível e o enunciável, é preferencialmente o espaço da leitura, da crítica, portanto, de sua fabulação (para lê-lo com Roland Barthes). Poderia chamá-lo de arquivo-crítico. Este arquivo, tal como o conceito de história para Walter Benjamin, só pode ser lido, para escapar da imagem como museu, reservatório, mera conservação, como história a contra-pêlo. Também para o
${ }^{3}$ BUCK-MORSS, Susan. A tela do cinema como prótese de percepção. Cultura e Barbárie :

Florianópolis, 2009. 
defensor da história como anacronismo e arqueologia, este conceito é chave:

Tomar la história "a contrapelo" es ante todo invertir el punto de vista. Igual que la óptica moderna se fundó sobre un movimiento "a contrapelo" de la vieja teoria del rayo visual emitido por el ojo (en adelante es la luz que puede llegar al ojo, y no el ojo que lanza sus rayos hacia el objeto a ver (42)), del mismo modo la historia se funda - y recomienza - según Benjamin, sobre un movimiento "a contrapelo" de la antigua búsqueda del pasado por el historiador.” (DIDI-HUBERMAN, 2006, p.135).

A propósito de uma teoria da imagem, há que se reportar ao estudo das estereoscopias e sua relação com o infraleve, que Raul Antelo aborda ao analisar as incisões duchampianas na América do Sul, tomando como ponto de observação o Rio da Prata : "La estereoscopia es así una manera de desarrollar ló infraleve ya que, como la fija en sus Notas , la imagen escindida destaca la diferencia dimensional entre dos objetos producidos en serie y de cuyo contraste se obtiene la máxima precisión conceptual.” (ANTELO, 2006, p.17). Mais adiante, ao seguir o rastro estrelar de Rubem Darío e Cruz e Sousa, Raul Antelo discute o regime paranoico da modernidade, uma vez que não haveria “originalidade subjetiva”, nem um "puro sentir”. A saída estaria em articular "uma dicção poética e uma ficção crítica, capazes de suportar a ruptura com a ordem simbólica. A paranoia é, assim, ela mesma, uma forma de atividade original.” (ANTELO, 2006, p.107). Poderíamos estender a experiência poética em crise para o campo da narrativa (Raul levanta a hipótese de que "Se a experiência poética está sempre em crise é porque, longe de acumular-se, ela se dissemina em constelações. (ANTELO, 2006, p.109) )”. Restaria ao sujeito “decidir a partir do indecidível”. Vejamos:

Adoptada esa decisión, que es, simultáneamente singular y múltiple, resulta más claro recapitular la teoria del sujeto implícita en este recorrido. Un sujeto, un “modo-de-ser”, nos dicen estos artistas, nada tiene de material: no es una sustancia puesta que se articula a partir de un procedimiento óptico de indescernibilidad intrínseca que impide toda sustancialidad e, incluso, cualquer puntualidad. Un sujeto se comprende en proceso, en constelación, en diseminación. (...) Un sujeto, como vemos, no es consecuencia, sin que por ello se transforme en el origen de una situación.” (ANTELO, 2006, p.109)

Portanto, o debate aqui sobre a imagem está longe de assemelhar-se àquele da constituição de uma figura e de seu potencial de referencialidade, que, acreditava-se, verdadeiramente possível. Um dos livros encontrados na biblioteca muriliana poderia ilustrar esse caráter pedagógico com que se aliava a ideia de um objeto a sua representação. É o caso de um Dicionário gráfico e etimológico da língua espanhola, intitulado A palavra pela imagem (GILBERT, 1946), cuja proposta é vincular imagem-conceito pelo denominado sistema Duden. Segundo explicação próloga, este sistema consiste em: 
Sabido es que, al confeccionar un diccionario, una de las mayores dificultades que se presentan es la de tener que dar, en forma aislada, el contenido justo de un sinfin de palabras que solo tienen sentido perfecto cuando aparecen unidas al todo de que forman parte. Para dar el valor exacto de una palabra y, sobre todo, la acepción precisa de uma voz técnica, lo ideal sería no separarla del conjunto a que pertenece, sino conservarla en ló que podríamos llamar su "médio ambiente". El propósito es, desde luego, plausible: pero las dificultades que ofrece son muchas, porque no siempre un dicionario de "orden alfabético" puede relacionar entre si, en un conjunto sintético, las palabras que atañen a una misma materia. (GILBERT, 1946, p.5)

O livro é dividido em 12 grupos e há 344 subdivisões. Há seção para “Mitologia e religião”, “Estado”, “A sociedade”, “O homem, a família e o lar”; Portanto, através de uma busca por palavra, se pode chegar à definição procurada. Caso se conheça a palavra, pode-se consultar ao final do livro o vocábulo “onde se dá a referência exata da lâmina (...) e do lugar fixo (...) que ocupa no desenho o objeto buscado” (p.6, tradução minha). Logo se nota que este modelo foi o que, durante anos, serviu de base para o trabalho pedagógico, especialmente para os Anos Iniciais, em que cada elemento presente no mundo pudesse encontrar um correspondente verbal e vive-versa, como se a imagem fosse capaz de datar, localizar, com precisão cirúrgica, este mesmo mundo.

O mundo do arquivo, ou seu meio ambiente, estaria para outro conceito, portanto. A ideia de tomar o arquivo não como produto acabado, mas como um dispositivo, com uma estrutura em que se formam/inventa(ri)am genealogias, aproxima-se do modelo deleuziano e de seu conceito rizomático. No arquivo, não há hierarquias para o pesquisador, ainda que a sua estruturação apresente uma ordem, com todos os elementos devidamente catalogados, fichados e, no caso de Murilo Rubião, com um conjunto arquivístico pré-estabelecido pelo autor (livros encadernados; documentos separados por categorias, cada um guardado em pastas separadas e em gavetas de arquivo de metal...). O trabalho crítico aproxima-se, aqui, ao do método intuitivo, em que uma espécie de mise èn cene leva-o à vertigem, não apenas porque há uma intenção de ali conhecer o que há, nem tampouco porque o pesquisador lida com uma sequência de ordenações (o arquivo dentro de uma biblioteca; o bibliotecário que fichou o material; o autor que ordenou todo seu legado e, finalmente, o pesquisador que reordena todos os materiais), mas, quiçá, por uma emergência de superpor, cruzar, ativar a sua biblioteca interior. É Deleuze, sobre Bergson, quem afirma:

La intuición no es la duración misma. La intuición es más bien el movimiento por el que salimos de nuestra propia duración, por el que nos servimos de nuestra duración para afirmar y reconocer inmediatamente la existencia de otras duraciones por encima o por debajo de nosotros. (...) Así, pues, la 
intuición forma ciertamente un método con sus três (o cinco ) reglas. Es un método esencialmente problematizante (crítica de los falsos problemas e invención de los verdaderos), diferenciante (divisiones e intersecciones), temporalizante (pensar en términos de duración). (DELEUZE, 1996, pp.31-34)

A referência a Deleuze põe em cena a noção de cruzamento de tempos, com o que se poderia pensar não mais “O que é um arquivo”, mas “Quando é um arquivo?”. Ideia também transformada em adiamento, em última instância, em retard, para Didi-Huberman, na imagem sugerida por Flora Sussekind de um Brasil que ainda não chegou, O Brasil não é longe daqui (SUSSEKIND, 1990). Portanto, mais do que a união de um espaço-tempo, o arquivo reúne dispersando, constituindo-se uma espera, ao que se poderia afirmar, com Mário de Andrade e Walter Benjamin, uma promessa de felicidade. O procedimento corresponde ao da imagem em movimento, a qual, para Deleuze, se condensa na figura do transdutor, dispositivo que converte a energia de uma forma à outra:

Poderíamos conceber uma série de meios de translação (trem, carro, avião...) e, paralelamente, uma série de meios de expressão (gráfico, foto, cinema): a câmera surgiria então como um transdutor, ou melhor, como um equivalente generalizado dos movimentos de translação. (DELEUZE, 1985, p.13)

Lidar com esses movimentos representa uma tarefa de permanente estado de impermanência, ou seja, de flutuação. Jean Bellemin-Nöel afirma que "Não distinguindo um sujeito de um objeto, ela (a psicanálise) nega que exista um sujeito definido ou definível, e objetos de pensamentos que não sejam habitados, desviados pelas artimanhas, tentativas, desejos de uma parte do sujeito” (BELLEMIN-NÖEL, 1988, p.9). Para des-montar o arquivo, essa caixa preta, esse vazio, a translação é necessária. O arquivo reveste-se de um aura de presença-ausência, como o autor, como o fantasma do autor. Giorgio Agamben também postula essa ideia. Em "O autor como gesto”, ao qual poderíamos acrescentar, como jogo, o escritor de Homo saccer, retomando Foucault, afirma que

(...) la función-autor aparece como proceso de subjetivación através del cual un individuo es identificado y constituído como autor de un determinado corpus de textos. De allí que, de este modo, toda indagación sobre el sujeto en cuanto individuo parece tener que dejar lugar al regimen que define en qué condiciones y bajo cuáles formas el sujeto puede aparecer en el orden del discurso. En este orden de cosas (...) "la huella del escritor está solo en la singularidad de sua ausencia; a él le corresponde el papel del muerto en el juego de la escritura”. El autor no está muerto, pero ponerse como autor significa ocupar el puesto de un muerto. (AGAMBEN, 2005, p.85) 
Inventar o lugar do arquivo é a ponta de lança do século, para sair do arquivo-mundo-museu como espaço de acumulação, já incapaz de profanar. Há que profanar o arquivo, dirá Agamben, desativando um velho uso e tornando-o inoperante, advertindo que “A profanação do improfanável é a tarefa política da geração que vem” (AGAMBEN, 1995, p.119). Por falar em des-ativar, na concepção de Roland Barthes, ao apresentar as múltiplas possibilidades de uso do Neutro para as aulas e seminário ministradas no Collège de France entre 1977-1978, numa mostra clara de como cintilar um conceito, defende que o Neutro deve ser pensado, meditado, assumido, enfim, fazê-lo ser desejado, a partir do que ele chama de "imagens em mim: meu imaginário do Neutro” (BARTHES, 2003, p.168). Ao defender que o Neutro recusa o princípio da classificação hierárquica, da premiação, buscando uma relação justa com o presente, deveríamos nos entregar à "banalidade que há em nós”,

(...) essa banalidade é sentida e assumida no contato com a morte: sobre a morte sempre só há pensamentos banais $\rightarrow$ Neutro seria o movimento mesmo,não doutrinal, não explicitado e sobretudo não teológico, que vai em direção a certo pensamento da morte como banal, pois, na morte, o exorbitante é seu caráter banal. (BARTHES, 2003, p.172)

Mas não pensemos que esta trivialidade, com que poderíamos ler frivolidade, na versão de Valery Larbaud (LARBAUD, 2001, p.188), está no arquivo gratuitamente. Nela, essa vida nua abdica de seu caráter naturalizante para ser, ele também, um constructo, uma montagem. Pensemos que o arquivo funciona como prótese (WILLS, 1995, pp.44 e 45) do próprio escritor, espaço em que ele se deixa levar por toda a sorte de pensamento-atividade-memória. Mas não indiferente a isso, ele constrói o seu legado à posteridade. Voltando ao caráter da relação da banalidade e à morte, pode-se pensar que a literatura muriliana funda-se a partir dessa ideia de total negação, de si e do mundo, com que uma morte incessante não se pode interromper (Vide $O$ ex-mágico). Outro momento fundador aparece na confissão que faz a Mário de Andrade, diante do arrojo e titubeio dos primeiros passos. Em carta a Murilo Rubião, datada de 5 de outubro de 1944, Mário redige um belo texto, uma carta de apego e desassossego, em relação a tudo e ao próprio Murilo. Reclama a falta de amigos, ainda que os tenha, para apontar:

Tudo em você é necessidade e controle. E faz parte dessa necessidade, em você, não a "devassidão” da inteligência, o uso voluptuário do pensamento (...) mais que isso, em você, uma força devastadora de inteligência, não sei como diga, a devastação da inteligência, uma inteligência que tem sua própria natureza, a precisão de se devastar a si mesma. É um bem? É um mal? Antes de mais nada: é uma natureza, é um caráter. E não tem caráter que não seja utilizável, nem natureza que a gente não possa tornar fecunda e grande. (...) Eu imagino que onde você se devasta perigosamente é na esperança abusiva de encontrar a expressão perfeita e única do que você quer 
dizer. O Diabo tanto consertou o ôlho do filho que furou. Você já refletiu bem sobre êsse preconceito de que uma ideia, uma imagem só podem se revestir duma expressão única? (...) Você positivamente não sabe, não pode saber, o número que a roleta vai dar, mas que eu saiba jamais o jogador se suicida, antes de perder o jogo. É o caso. O jogador joga pensado e procura acertar. Mas não se devasta no suicídio, joga. Procure acertar mas não se devaste também. Nem antes, nem depois. Porque depois da obra lançada, entra o esportismo franco da vida que em vez da devastação e do suicídio, nos leva nobre ou sadiamente a reconhecer que perdemos. O seu exaspero da expressão é positivamente um suicídio. É mau isso. (ANDRADE, 1995, pp.75-77)

Mário de Andrade retoma o assunto na derradeira missiva que se tem notícia, datada de 02 de dezembro de 1944. Entre a ficção e a sensibilidade “tão estranha, entranhada e intrincada” (p.89) de Murilo [com que se lê, dos artistas], o autor de Macunaíma busca nos desvãos dos primeiros passos não desanimar o escritor novo, apontando que, ao lado do suicido, quando aparece uma "renúncia do amor enquanto elemento psíquico da vida e experiência psicológica do viver”, o escritor deve tentar, exercitar, para um dia não se lamentar pelo que deixou ou não tentou.

A carta ensaia uma posição que Murilo exercita ao longo de toda a sua vida: uma reescritura de si, como que sempre apostando nesse jogo. Uma morte anunciada que ele tenta protelar em nome de uma escrita enxuta, e por vezes exausta ${ }^{5}$. Em ensaio continuado, a saber, retomado e retrabalhado, Eneida Maria de Souza pontua, em A crítica biográfica, postula uma escrita ficcional, onde o trabalho de hibridização é de sua própria natureza. Afirma:

Outras indagações referentes à autoficção conduzem à desestabilização do referencial, ao seu deslocamento, assim como aos deslocamentos espaçotemporais [típicos em Murilo], considerando serem os protocolos enunciativos mais livres. (...) A desestabilização do referencial produz, com efeito, a invenção e a estetização da memória, esta não mais subordinada à prova de veracidade.(SOUZA, 2011, p.23)

Obviamente não se trata de ler a produção ficcional de Murilo como autobiografia, mas de pensar o lugar do arquivo neste entre-lugar, uma vez que é um espaço da interioridade, quase da confissão (a si mesmo), que nutre os textos chamados de ficcionais ${ }^{6}$. Para tratar da questão do arquivo como espaço movente, híbrido, há que vê-lo como constituído por partes, restos. Ou seja, há que pleitear, na leitura das notas, de frases soltas, de textos mais complexos, uma teoria do resto, escatológica, com que a noção de ruína pode lançar luzes aos escombros. Escombros que se assemelham ao trabalho de coletar aos poucos impressões; anotar fatos dispersos; ensaiar escritas, como em um caderno de anotações. Ao tentar discutir o que é literatura, o escritor César Aira parece não concordar com uma prática de escrita aos poucos, rapsódica, em notas. Estabelece quatro longos arrazoados para
${ }^{5}$ Procurei desenvolver algumas linhas fantasmáticas ao estabelecer um prototexto para um dos contos de Murilo em A exaustão da palavra - Um prototexto para Marina, a Intangível de Murilo Rubião. 1992, 174

f. Dissertação (Mestrado em Literatura Brasileira e Teoria Literária) Universidade Federal de Santa Catarina, 1992.

${ }^{6}$ Para um debate sobre o assunto, consultar HAY,

Louis. A literatura

dos escritores

: Questões de crítica genética.

Trad. Cleonice Paes Barreto. Belo Horizonte : UFMG, 2007, especialmente em "O manuscrito entre texto e traçado", onde defende a ideia do manuscrito como objeto (pp.148-156). Também, o clássico livro, agora revisado, de LEJEUNE, Philippe. $O$ pacto autobiográfico - De Rousseau à Internet. Trad. Jovita Maria

Gerheim Noronha e Maria Inês Coimbra Guedes. Belo

Horizonte : UFMG, 2008. 
tanto, não hierarquicamente, para concluir que o passar de uma nota a outra exigiria um trabalho de tradução, o que comprometeria permanentemente o trabalho. Afirma que:

O gênero “caderno de notas” propõe um bom problema sobre o qual valeria a pena fazer uma teoria: se alguém toma notas de tudo o que acontece ou lhe ocorre ou sugerem suas experiências ou leituras, pode fazer com elas um texto contínuo? Quais são as condições de possibilidade ou de existência desse discurso?(...) Ou, visto de outra perspectiva, não haveria em todo discurso, mesmo no mais firmemente encadeado, uma fragmentação irredutível, reflexo da irredutibilidade do pensamento ao tempo? Se é assim, e parece o mais provável, toda transição seria um simulacro, uma invenção submetida à arte, com o que seria possível telas tão boas e eficazes a ponto de conectar os pensamentos mais incongruentes. (AIRA, 2011, pp.13-14)

Encadeado à questão da tradução, Aira alude a outro ponto, para ele intrínsico para quem elabora textos dessa forma, a de que toda nota seria uma citação proveniente de outro, da qual seríamos apenas destinatários, levando-nos à questão do narrador, "criador por excelência de continuidade, e nesse sentido, o antifilósofo.”(p.15). No entanto, a afirmação mais contundente vem a seguir, ao enunciar que

Jamais se deveria corrigir o escrito para torná-lo melhor. Corrigir é invocar um fantasma. Eu escrevo como quem sou, mas se o escrito estivesse melhor escrito seria como se outro o tivesse escrito, algum grande escritor. (...) quando um escritor corrige o que escreveu, o faz com um olhar ( e uma estética, e uma moral) de leitor, não de escritor; está se rebaixando a fazê-lo ao gosto do leitor, com o que, além de renunciar a sua função específica, inibe a surpresa, que é o gozo primeiro e último da leitura. (...) Uma correção realmente exaustiva (e para que corrigir se não é para fazê-lo bem, quer dizer, para fazê-lo por inteiro?) deveria dar por resultado um texto que o leitor já conheça. (AIRA, 2011, p.26)

Nesse caso, todo o arquivo seria impossível, execrável. Ou seja, não poderia/deveria existir, menos ainda o trabalho intenso e exaustivo de reescritura. Se retomamos a noção de citação, vamos nos deparar com outra concepção. No caso de Murilo, esta é fundamental, uma vez que é ela quem anuncia o texto, com seu trabalho intrincado e persistente das epígrafes. Antoine Compagnon, que dedicou um livro todo a esse respeito, constrói seu texto exatamente como um enjambement, costurando cada parte deixada em suspenso ao final de cada tópico, sendo retomada em seguida, no próximo. Em um deles, Uma canonização metonímica, declara:

Bendita citação! Ela tem o privilégio, entre todas as palavras do léxico, de designar ao mesmo tempo duas operações - uma, de extirpação, outra, de excerto - e ainda o objeto dessas duas operações - o objeto extirpado e o objeto enxertado - como se ele permanecesse o mesmo em diferentes 
estados. Conheceríamos em outra parte, em qualquer outro campo da atividade humana, uma reconciliação semelhante, em uma única e mesma palavra, dos incompatíveis fundamentais que são a disjunção e a conjunção, a mutilação e o enxerto, o menos e o mais, o exportado e o importado, o recorte e a colagem? Há uma dialética toda-poderosa da citação, uma das vigorosas mecânicas do deslocamento, ainda mais forte que a cirurgia. (COMPAGNON, 2007, p.33)

Compagnon concluirá com Mallarmé sua exposição, com uma citação do mesmo no corpo de seu texto [agora minha] de que “““O livro” (...) expansão total da letra, deve tirar dela, diretamente, uma mobilidade e, espaçoso, por correspondência, instituir um jogo, não se sabe, que confirme a ficção.””(p.163). Haveria um sujeito que deveria se mover permanentemente, porque o universo está em variação constante: "Num universo essencialmente móvel, a citação, a repetição, o ciclo não é mais aquilo que põe o texto em movimento; daí as falhas, os acoplamentos, as ressonâncias. A citação é a marca de um acoplamento entre a maculatura e o histrião, uma aceleração instantânea do movimento, quando as trajetórias separadas entrem em ressonância.” (p.165) Portanto, parece-me que Aira, ao postular um modelo mais integra", não repetitivo, sem erros trabalhados no caderno de notas, remete a um tipo de literatura que os escritores não deveriam praticar. Se o fazem, perdem a aura, porque tornam-se leitores, o que para Compagnon é tido como elemento constituinte do processo cambiante da leitura/escritura. Em se tratando de metonímia, vejamos a posição de Gilles Deleuze, para quem, talvez como Cioran, o processo de corte/montagem, ou seja, a interrupção, é constituinte da obra.

O tempo permanece uma imagem indireta que nasce da composição orgânica das imagens-movimento, mas tanto o intervalo quanto o todo adquirem um novo sentido. O intervalo, o presente variável, tornou-se o salto qualitativo que atinge a potência elevada do instante. Quanto ao todo como imensidão, não se trata mais de uma totalidade de reunião, que subsume partes independentes desde que existam umas para as outras, e que sempre pode ser aumentado se acrescentarmos partes ao conjunto condicionado, ou se reportarmos dois conjuntos independentes à ideia de um mesmo fim. É uma totalidade que se tornou concreta ou existente, onde as partes se produzem uma pela outra em seu conjunto, e o conjunto se reproduz nas partes, de tal modo que esta causalidade recíproca remete ao todo como causa do conjunto $e$ de suas partes segundo uma finalidade interior. (DELEUZE, 1985, p.53)

O inacabado, portanto, é constituinte do arquivo assim como o texto pronto, acabado parece impor uma eternidade, ainda que passageira. Assim como o sistema Duden buscava dar conta da realidade, nomeando-a e apontado seu correlato no campo da imagem, poderíamos ler esse sistema nominal (catalográfico, princípio enciclopédico) como fundamental no ar- 
quivo. Funcionaria, por assim dizer, como o processo palimpsístico, em que muitas ideias vão sendo trabalhadas, muitas vezes simultaneamente, fazendo com que essa borra permaneça no fundo, escondida, enquanto sentimos o aroma da página nova editada. Esse sistema nominativo aparece no livro Ideia de prosa (AGAMBEN, 2012), em que as anotações, aparentemente desconexas, ao acaso, vão se somando, como num bloco de notas... Como uma obra aberta, o texto se expande como num Limiar, onde há uma defesa prévia das relações da operação de leitura, argumentando que tanto quem escreve como quem lê se transformam em anotadores. Estaria na constituição do próprio arquivo o ato semelhante ao que defende em ideia de vocação, ou seja, a de que não se poderia conservar uma fidelidade sem nunca a formular, nem sequer a si próprio. O bloco de notas (portanto, o arquivo) serve como repositório do processo de lembrança/esquecimento. Agamben dirá que "Aquilo que se esqueceu não foi simplesmente anulado, posto à parte: foi consignado ao esquecimento.” (p.37), com que a ideia de uma infidelidade seria inerente ao processo de escrita. Pouco adiante, retomando Nietzsche, afirmará:

Este monstruoso compromisso entre destino e memória, no qual aquilo que só pode ser objeto de recordação (o retorno do idêntico) é vivido todas as vezes como um destino, é a imagem distorcida da verdade, que o nosso tempo não consegue dominar. Porque a abertura da alma - a verdade - não se abre sobre o abismo de um destino infinito nem se fecha na eterna repetição de um estado de coisas, mas, abrindo-se num nome, ilumina apenas a coisa e, fechando-se sobre ela, apreende ainda a sua própria aparência, recorda-se do nome. (AGAMBEN, 2012, p.47)

Em Uma nota de rodapé, texto que Silviano Santiago publica alguns anos antes de seu aparecimento na Revista do Arquivo Público Mineiro (SANTIAGO, 2007), o crítico também vai ater-se a um nome, para desembalar da biblioteca, arqueologicamente, o vocábulo arquivo, partindo do conhecido livro de Jacques Derrida, $\mathbf{O}$ mal de arquivo. Recupera, assim, o duplo sentido presente na palavra arkhé: tanto commencement (começo) como commandement (mandamento e/ou comando). Para o autor de $\mathbf{O}$ cosmopolitismo do pobre, Derrida busca essa origem através de uma falta, uma ilusão de ouvido:

Onde deveria ser oferecida ao ouvido do espectador uma reflexão filosófica sobre a dita memória e a dita questão do arquivo, lhe estão sendo oferecidos, em sucedâneo e pelo lexicógrafo doublé de filósofo, a "memória" e o "arquivo" dum vocábulo grego, memória e arquivos esses que serão "abrigados" na atualidade pelo vocábulo neolatino archive, que, por sua vez, virá abrigar a todos os intermediários nas páginas seguintes da conferência. A ilusão de ouvido é, pois, aparente, já que tanto a questão da "memória” e quanto a questão o conceito de "arquivo" têm valor concreto e intercambiável graças ao arquivo do vocábulo arkhé que nos é oferecido. (SANTIAGO, 2007, p.133).

\footnotetext{
${ }^{7}$ Consultar "Ideia do nome", onde Agamben distingue o plano, na filosofia antiga, do nome do plano do discurso, apontando para a fratura da linguagem, a impossibilidade de dizer tudo que foi invocado (p.103).
} 
Vale destacar que Silviano recupera essa ideia da palavra em estado de dicionário ${ }^{8}$, com o que o verbete aponta para uma tradição que requer, no caso da psicanálise, a figura da 'consignação', remetendo a ideia de guarda, confiar, mas também a de reunir, juntar signos. Um dos objetivos do crítico é lembrar que Derrida esquece um significado recente do verbete, o qual seria a de que consignar é também proibir a entrada em um local, segundo o Petit Robert, ideia importante que nos devolve as interdições para se consultar um arquivo, o que se torna um problema político, a questão da corporação dos historiadores, especialmente na França, o que leva Silviano a debater o livro de Sonia Combe, Archives Interdites. Les peurs françaises face à'histoire contemporaine para chegar, entre outras questões, ao endereço eletrônico do Arquivo de Segurança Nacional americano, mantido por uma biblioteca e um instituto de pesquisa, geridos por organização não-governamental (www.gwu;edu/ nsarchiv/nsa/the_archive.html). Toda a problemática e especificidade do arquivo traz consigo também a ideia da hereditariedade, ou melhor, de uma potência paterna, entendida aqui como o legado deixado/adquirido. Este tópico, de caráter relevante para a cultura de um país, de um povo, pode ser analisado sob diversas faces. A questão da tradição literária é uma delas. No caso de Murilo Rubião, além de enfrentar a tradição machadiana, à qual era fiel seguidor/traidor, pode-se ler o seus trabalhos também como uma contestação ao passado. Como sair da tradição paterna? ${ }^{9}$

Não distante do início da produção literária de Murilo Rubião, publicava-se em Belo Horizonte a revista Leite Criôlo (1929), sendo relançado recentemente seu fac-símile com anotações críticas. Nesta edição, é possível encontrar, em um dos estudos, a apreciação de Fernando Correia Dias. Nele, um dos aspectos enfocados é a divisão enfrentada sobre o nacionalismo apresentado à época. Vejamos:

Diz [Carlos Drummond de Andrade] que a tendência dos componentes do agrupamento era de valorizar o conceito de nacionalismo. Acredita, no entanto que isso tenha sido influência de Mário de Andrade, cujas ideias a respeito derivavam do amor ao Brasil, por ter nascido aqui. (...) "Mas nós não assimilamos bem. Eu não assimilei o conceito nacionalista de Mário (CURY, 1998, p.159).

\section{(...)}

E leite criôlo? Este era radicalmente nacionalista. Veja-se a opinião de Achilles Vivacqua, num texto, “Criôlo" (...):

"o criolismo tem como característica o super nacionalismo. Combate a cultura extra-nacional do nosso povo. Povo que ainda vive a pensar, a sentir, a escrever ... até morrer, em plena terra brasileira, à europeia.” Para ele, os portugueses e africanos eram estrangeiros.”

E João Dornas filho afirma que o criolismo - como a antropofagia - é um movimento "literário, filosófico e religioso, mas sem estrangice". Noutro momento declara que só os moços estão abertos ao "criolismo", pois os velhos estão intoxicados de estrangice. (DIAS, 2012, p.20)
${ }^{8}$ Raul Antelo, ao discutir a ideia de que toda arché é informe, cita Bataille: "Um dicionário começaria a partir do momento em que ele não desse mais o sentido das palavras, mas sim suas obrigações. Assim, o informe não é somente um adjetivo com certo sentido, mas um termo que serve para desorganizar, exigindo geralmente que cada coisa tenha sua própria forma. Isso que ele nomeia não aponta um caminho fixo e pode ser facilmente despedaçado, do mesmo modo que uma aranha ou um verme. De fato, para o contentamento dos acadêmicos, seria necessário que o universo tomasse forma. Toda a filosofia tem apenas um objetivo: trata-se de dar uma roupagem ao que já existe, uma roupagem matemática. Por outro lado, afirmar que o universo não se assemelha a nada e que ele não é nada além de informe retoma a afirmação de que o universo é algo como uma aranha ou um escarro.” BATTAILE, Georges, Informe. Documents, Paris, n.7, dez.1929 In ANTELO, Raul. O dispositivo Boitatá. Pensar/ escrever 0 animal ensaios de zoopoética e biopolítica. Org. Maria Esther Maciel. Florianópolis : UFSC, 2011, p. 289.

${ }^{9}$ A esse respeito, escrevi um pequeno ensaio intitulado $A$ voz rouca em arquivo silencioso, apresentado no VIII Congresso Internacional ABRALIC 2002 - Mediações. Belo Horizonte : UFMG, (CD). 
É este boa parte do cenário recebido por Murilo. Não sem razão, Mário e os novos trocam intensa correspondência. O impasse criado nos meios acadêmicos, literários, culturais deixava claro que as tendências não se assimilavam de todo (em parte, este era uma das intenções do movimento). Trocando em miúdos, a Murilo cabia, neste caso, aceitar um nacionalismo modernista não compreendido ou aderir ao um super nacionalismo mineiro. Leite criôlo é publicado à época em que outra tradição paterna marca sua presença: o próprio pai de Murilo, lançando livros de sonetos, fábulas, aparentemente desconectado do movimento modernista. Veja-se, por exemplo, o título: Nos caminhos do evangelho (RJ, 1939), todo em verso; No horto suave da legenda (SP : Casa Mayença, 1923) ${ }^{10}$ ou ainda um livro meramente gramatical, sobre pontuação. Portanto, Murilo busca encontrar uma diç̧ão própria, em uma terra cercada por montanhas, e a questão do eco, como ele escreverá em Ladrões mineiros (RUBIÃO, 1947) ${ }^{11}$, estará muito presente. Esta perspectiva do legado, da tradição, do local em luta com um desejo de independência, arrojo, também são notados em outro artigo de Silviano Santiago, Drummond (SANTIAGO, 2013, pp.8-13), texto lido na abertura da 10a . Flip - Festa Literária Internacional de Paraty, em 4 de julho de 2012. Tentando reconstruir a trajetória do escritor, Silviano assinala que:

O sucesso de público de Drummond, a validade do seu texto em termos estéticos, históricos e sociológicos, a unanimidade em torna da escolha da sua obra poética como a mais significativa do Modernismo brasileiro, tudo isso advém do fato de que a sua poesia dramatiza de forma complexa e original a oposição e a contradição entre Marx e Proust, entre a revolução político-social, instauradora de uma Nova Ordem Universal, e o gosto pelos valores tradicionais do clã familiar dos Andrades, seus valores socioeconômicos e culturais.

(...)

Por mito de começo entende-se o desejo de Drummond em inaugurar, por conta própria, uma nova sociedade em que pode negar totalmente os valores do passado rural e do clã. (...) Por mito de origem entende-se a vontade de o poeta Drummond inscrever seu projeto de vida numa ordem sociocultural mineira, em que os valores fortes da individualidade e da rebeldia perdem a razão de ser, já que são meros indícios de insubordinação passageira. (SANTIAGO, 2013, pp.9-10)

Esse desejo de romper com o passado e inaugurar "novos antepassados em uma nova cidade" vai cedendo espaço para a herança, "bens de família, bens simbólicos que, em última e derradeira instância, determinam a posição sócio-política e econômica do Poeta” (p.12). Ou seja, ao assumir o discurso do Pai, Drummond teria esquecido de seguir desbravando novos rumos e acomodou-se nas instalações de seus antepassados, materializadas no antigo Sobrado mineiro ${ }^{12}$. Como se vê, o impasse era mais gigantesco do que se imaginava.
${ }^{10} \mathrm{O}$ livro trata de fábulas, que o autor resolveu adaptar e recontar. Em uma delas, "Era uma vez um príncipe encantado”, temos a presença da figura de dragões, que será retomada por Murilo muitos anos mais tarde. O livro é dedicado a Maria Antonieta F. Rubião. O exemplar constante da biblioteca de Murilo apresenta uma dedicatória ao sogro. Certamente, oferecido pela própria Maria Antonieta.

${ }^{11}$ Vale lembrar que se trata de uma crônica, gênero que Murilo praticou, às vezes com pseudônimos (Rosendo, por exemplo), especialmente nas décadas de 30 e 40.

${ }^{12}$ Silviano encerra com o fragmento "É teatral a escada de dois lances/Entre a rua e os Andrades./ Armada para a ópera? ou a ponte/Para marcar isolamento?”. (p. 12). 
O trabalho que se configura diante do material deixado propositalmente por um escritor, inclusive as cartas, tem a ver com o cartão postal, de Jacques Derridá: um texto aberto, mas impossível de se ler no todo:

(...) as cartas são sempre cartões-postais: nem legíveis nem ilegíveis, abertas e radicalmente ininteligíveis (...) a carta se dispersa ou logo se multiplica, eco dividido dela própria (ela consiste, enfim, apenas no seu próprio suporte, não é nada menos do que ideal e pode, portanto, destruir-se sem permanecer), ela está perdida para o destinatário no próprio momento em que se inscreve, sua destinação é então imediatamente múltipla, anônima(...). (DERRIDA, 2007, p.92)

Assim como o trabalho de René Magritte, o que se nos apresenta é algo semelhante: poderíamos dizer que Isto não é um arquivo. Ou ainda: ele ainda não chegou, o que nos levaria a pensar no arquivo enquanto espera. $\mathrm{O}$ arquivo que ainda não foi. Um passado que ainda não passou.

\section{Referências}

AIRA, César. Nouvelles Impressions du Petit Maroc. Trad. Joca Wolff (edição bilíngue). Desterro, Florianópolis : Cultura e Barbárie, 2011.

AGAMBEN, Giorgio. Profanaciones. Trad. Flavia Costa e Edgardo Castro. Buenos Aires : Adriano Hidalgo, 2005.

Ideia da prosa. Trad. João Barrento. Belo Horizonte : Autêntica, 2012.

AGUILAR, Gonzalo. Por uma ciencia del vestígio errático. (Ensayos sobre la antropofagia de Oswald de Andrade). Grumo : Bueno Aires, 2010.

ALENCAR, João Nilson P. de. A exaustão da palavra - Um prototexto para Marina, a Intangível de Murilo Rubião. 1992, 174 f. Dissertação (Mestrado em Literatura Brasileira e Teoria Literária) - Universidade Federal de Santa Catarina, 1992.

.Avoz rouca em arquivo silencioso. VIII Congresso Internacional ABRALIC 2002 - Mediações. Belo Horizonte : UFMG, (CD).

. O corpo (mutilado) do arquivo. Suplemento Literário Minas

Gerais. n.1.347. Belo Horizonte : Secretaria de Estado e Cultura, março/ abril 2013.

ANDRADE, Mário de. Mário e o pirotécnico aprendiz - Cartas de Mário de Andrade e Murilo Rubião. Belo Horizonte : UFMG; São Paulo : IEB-USP; São Paulo : Giordano, 1995.

ANTELO, Raúl. Potências da imagem. Chapecó : Argos, 2004.

Maria con Marcel - Duchamp en los trópicos. Bueno Aires :

Siglo XXI Ed. Argentina, 2006. 
Ausências. Florianópolis : Editora da Casa, 2009.

O dispositivo Boitatá. Pensar/escrever o animal - ensaios de zoopoética e biopolítica. Org. Maria Esther Maciel. Florianópolis : Ed. UFSC, 2011.

BARTHES, Roland. O neutro. Trad. Ivone Castilho Benedetti. São Paulo : Martins Fontes, 2003.

BELLEMIN-NÖEL, Jean. Textanalyse et psychanalyse. Interlignes. Essais de textanalyse. Presses Univesitaires de Lille, 1988.

BUCK-MORSS, Susan. Dialética do olhar - Walter Benjamin e o projeto das Passagens. Trad. de Ana Luiza de Andrade. Belo Horizonte : UFMG; Chapecó : Universitária Argos, 2002.

. A tela do cinema como prótese de percepção. Cultura e Barbárie : Florianópolis, 2009.

COMPAGNON, Antoine. O trabalho da citação. $1^{\text {a }}$. reimpressão. Trad. Cleonice P. B. Mourão. Belo Horizonte : UFMG, 2007.

DELEUZE, Gilles. Cinema 1- a imagem-movimento. Trad. Stella Senra. São Paulo : Brasiliense, 1985.

. El bergsonismo. 2a . ed. Madrid : Cátedra, 1996.

. Conversações. $4^{\text {a }}$. reimpressão. Trad. Peter Pál Pelbart. Rio de Janeiro : 34, 2004 (Coleção TRANS).

DERRIDA, Jacques. O cartão-postal - De Sócrates a Freud e além. Trad. Ana Valéria Lessa e Simone Perelson. Rio de Janeiro : Civilização Brasileira, 2007.

DIAS, Fernando Correia. Prefácio. Leite criôlo (fac-símile). Belo Horizonte : Instituto Cultural Amilcar Martins, 2012, p. 20. Organizadores : FILHO, Amilcar Vianna Martins e CABRAL, Cleber Araújo.

DIDI-HUBERMAN, Georges. Ante el tiempo- Historia del arte y anacronismo de las imágenes. Trad. Oscar Antonio Oviedo Funes. Buenos Aires : Adriana Hidalgo, 2006 (Filosofia e Historia).

2a.ed., São Paulo : Ed.34, 2010.

O que vemos, o que nos olha. Trad. Paulo Neves.

HAY, Louis. A literatura dos escritores : Questões de crítica genética. Trad. Cleonice Paes Barreto. Belo Horizonte : UFMG, 2007.

HUIZINGA, Johan. Homo ludens: O jogo como elemento da cultura. $7^{\mathrm{a}}$.ed. Trad. João Paulo Monteiro. São Paulo : Perspectiva, 2012.

IANNACE, Ricardo. Retratos em Clarice Lispector - Literatura, pintura e fotografia. Belo Horizonte : UFMG, 2009. 
GILBERT, J. (Dir.) LA PALAVRA PELA IMAGEN (Sistema Duden) Diccionario gráfico y etimológico de la lengua española. . Barcelona : Ediciones HYMSA, 1946. LARBAUD, Valery. Sob a invocação de São Jerônimo. Trad. Joana Angélica. São Paulo : Ed. Mandarim, 2001.

RUBIÃO, Murilo. Ladrões mineiros. Revista Social Trabalhista. Belo Horizonte : Veloso \& Cia . Ltda. dezembro de 1947. . Anotações antigas para contos improváveis (pasta). Acervo dos Escritores Mineiros - Belo Horizonte : UFMG.

SANTIAGO, Silviano. Uma nota de rodapé. Revista do Arquivo Público Mineiro. Belo Horizonte, n.1, 2007. . Drummond. Suplemento Literário de Minas Gerais. Belo Horizonte, n.1346, 2013.

SOUZA, Eneida Maria de. Janelas indiscretas - Ensaios de crítica biográfica. Belo Horizonte : UFMG, 2011.

SUSSEKIND, Flora. O Brasil não é longe daqui. São Paulo : Cia. Das Letras, 1990.

WILLS, David. Prosthesis. California : Stanford University Press, 1995.

Recebido em setembro/2015

Aceito em dezembro/2015 